\title{
STABILISASI WARNA KAYU TUSAM (Pinus merkusii Jungh. \& de Vriese) DAN KEMIRI (Aleurites moluccanus (L.)Willd.)
}

\author{
Agus Ismanto \\ Pusat Litbang Hasil Hutan \\ Jl. Gunung Batu No. 5, Bogor 16001 \\ e-mail: aismanto59@gmail.com
}

\author{
ABSTRACT \\ Wood-Color Stabilization of Pine (Pinus merkusii Jungh. \& de Vriese) \\ and Pecan (Aleurites moluccanus (L.)Willd.)Wood
}

\begin{abstract}
Discoloration are generally caused by biological or non-biological factors in origin particulary for bright color wood such as pine and pecan. This paper evaluates the discoloration of normal pine wood (P. merkusii Jungh. $\&$ de Vriese) and pecan wood (Aleurites moluccanus (L.) Willd.) and find appropriate chemical treatments to maintain its natural wood color. Chemical treatments studied includes sodium suphite (SS), sodium bicarbonate (SB), sodium chloride (SC), stannous chloride(ST), and methylene bis thiocyanate (MBT) each solution with level of 2, 3, and $4 \%$. Wood color value before and after chemical treatments were measured using CDX's colour differencemeter based on three-dimensional color value CIELab ( $\left.L^{*}, a^{*}, b^{*}\right)$. Research showed that pine wood had a brightness value $(L *)$ higher than the pecan wood. Value $L *$ in between pine wood ranged from 70.6 to 78.1 (SB, Outdoor$M B T$, indoor), while at pecan wood was from 56.6 to 72.6 (SB, Outdoor-Untreated). The value of the color difference $(\triangle E)$ obtained the highest onthe stannous chloride brushed wood and the lowest value was found on untreated. In other chemical treatment had a more low more $\Delta E$ value, thus maintaining the hearts potentially natural color of wood.
\end{abstract}

Keywords: $\quad$ Wood species, brightness value $(L *)$, color difference value $\left(\Delta E^{*}\right)$,color degradation, blue stain

\begin{abstract}
ABSTRAK
Degradasi warna disebabkan oleh faktor-faktor biologis atau non-biologis khususnya pada kayu berwarna cerah seperti pinus dan kemiri. Tulisan ini mengevaluasi degradasi warna kayu pinus ( $P$. merkusii Jungh. \& de Vriese) dan kayu kemiri (A. moluccanus (L.) Willd.) normal, dan mempelajari bahan kimia dan metode yang tepat untuk mempertahankan warna alami kayu. Larutan kimia yang digunakan dalam penelitian ini yaitu sodium sulfit (SS), sodium bikarbonat (SB), sodium klorida (SC), stanium klorida (ST), dan metilen bistiosianat (MBT) masingmasing dengan kadar 2, 3, dan 4\%. Nilai warna kayu sebelum dan sesudah perlakuan diukur menggunakan alat pengukur warna Colour Difference Meter CDX menggunakan sistem tiga dimensi CIE Lab (L*, a*, b*). Hasil penelitian menunjukkan bahwa kayu tusam memiliki nilai kecerahan $\left(\mathrm{L}^{*}\right)$ lebih tinggi dibandingkan dengan kayu kemiri. Nilai L* pada kayu tusam berkisar antara 70,6-78,1 (SB, di luar ruangan-MBT, di dalam ruangan), sedangkan pada kayu kemiri adalah 56,6-72,6 (SB, di luar ruangan-kontrol). Nilai perbedaan warna $(\Delta \mathrm{E})$ tertinggi didapatkan pada kayu yang dilabur stanium klorida dan nilai yang terendah dijumpai pada kontrol. Pada perlakuan kimia lainnya memiliki nilai $\Delta \mathrm{E}$ lebih rendah, sehingga berpotensi dalam mempertahankan warna alami kayu.
\end{abstract}

Kata kunci: Jenis kayu, nilai kecerahan, nilai perbedaan warna, degradasi warna, jamur biru

\section{PENDAHULUAN}

Warna kayu merupakan salah satu ciri umum kayu yang dapat diamati tanpa menggunakan alat bantu. Menurut Uzunovic et al. (2008), perubahan warna kayu adalah perubahan yang menyimpang dari warna alami kayu, yang dapat disebabkan oleh dua faktor yaitu, biologis atau non-biologis. Perubahan warna secara biologis disebabkan antara lain oleh jamur biru (blue stain), mold, pembusukan atau bakteri, sedangkan perubahan warna secara non-biologis terjadi pada kondisi yang spesifik seperti disebabkan oleh faktor mekanis (tanda terbakar, kotoran), kimia, dan biokimia atau fotokimia (Uzunovic et al., 2008). Penggunaan suhu tinggi dalam pengeringan juga dapat mengakibatkan terjadinya perubahan warna yang disebabkan migrasi zat ekstraktif ke permukaan kayu (Dubey et al., 2010; Tian et al., 2010). 
Salah satu faktor penyebab perubahan warna yang sering dijumpai adalah akibat serangan jamur biru (Carey, 1975 dalam Martono, 2012). Serangan jamur biru menjadikan kayu yang awalnya berwarna putih/kuning cerah/merah muda berubah menjadi kebiru-biruan seperti dijumpai pada kayu tusam dan karet. Jamur biru menyerang jaringan parenkim pada kayu gubal, dan serangan umumnya terjadi pada saat kayu masih basah atau segar di lingkungan lembab dan suhu tinggi (Smith, 1977 dalam Martono, 2012).

Kayu tusam (Pinus merkusii Jungh. \& de Vriese) memiliki warna putih kekuningan. Kayu ini banyak digunakan untuk pekerjaan konstruksi berat maupun ringan seperti kusen jendela, pintu, tiang rumah, lantai, dan mebel (Lemmens et al., 1994). Dalam penyimpanan, kayu tusam mungkin mengalami perubahan warna secara alami akibat serangan jamur biru (Smith, 1977 dalam Martono, 2012).

Kayu kemiri (Aleurites moluccanus (L.) Willd.) juga merupakan kayu yang memiliki warna putih cerah. Kayu ini agak ringan dan tidak tahan lama. Meskipun tidak digunakan untuk konstruksi, tapi dapat digunakan untuk membuat mebel (de Guzman \& Siemonsma, 1999). Sama dengan kayu tusam, kayu kemiri juga mengalami perubahan warna alami dan mudah terserang jamur biru, seperti Botryodiplodia theobromae yang menginfeksi kayu penyebab jamur biru (de Guzman \& Siemonsma, 1999). Tulisan ini mengevaluasi perubahan warna alami kayu tusam dan kemiri serta mempelajari bahan kimia dan metode yang tepat untuk memperbaiki warna kayu akibat serangan jamur biru.

\section{BAHAN DAN METODE}

\section{Bahan dan Alat}

Bahan yang digunakan antara lain kayu tusam ( $P$. merkusii Jungh. \& de Vriese) dan kemiri (A. moluccanus (L.) Willd.) dari 5 pohon berumur 15-20 tahun, dengan tinggi berkisar antara 5-6 $\mathrm{m}$ dan diameter 25-30 cm yang diambil dari hutan rakyat di Kabupaten Kuningan dan Sukabumi, Jawa Barat.

Peralatan yang digunakan yaitu gergaji potong, gergaji belah, kipas angin, pengering vakum (vacuum dryer), ampelas kayu, kaliper, spidol, eksikator, hand sprayer, bak plastik, kuas, kantung plastik, dan plastik lembaran, sarung tangan, masker, rol meter, hygrometer, dan termometer, serta Portable Colour Difference Meter merek Murakami model CDX-105.

\section{Metode}

\section{Penyiapan Contoh Uji}

Contoh uji setiap jenis kayu berasal dari 5 pohon, setiap pohon diambil 3 dolok masing-masing ukuran panjang $2 \mathrm{~m}$. Kemudian dari tiap dolok tersebut digergaji hingga menghasilkan 12 papan dengan ukuran $2,5 \mathrm{~cm} \times 10 \mathrm{~cm} \times 50 \mathrm{~cm}$, sehingga jumlah papan yang dihasilkan untuk tiap jenis kayu sebanyak 180 keping.

\section{Prosedur Kerja}

Contoh uji dilabur dengan
menggunakan bahan kimia, yang sebelumnya diampelas terlebih dahulu menggunakan ampelas ukuran 400 Grit. Pelaburan dilakukan secara merata pada seluruh bagian contoh uji kayu dengan berat labur sebesar $200 \mathrm{~g} / \mathrm{m}^{2}$ mengacu metode Ismanto \& Iqbal (2013) dengan perlakuan sebagai berikut:

a. Tanpa perlakuan, sebagai kontrol (K)

b. Pelaburan dengan larutan natrium klorida/SC $(\mathrm{NaCl}) 2,3$, dan $4 \%$

c. Pelaburan dengan larutan natrium sulfit/SS $\left(\mathrm{Na}_{2} \mathrm{SO}_{3}\right) 2,3$, dan $4 \%$

d. Pelaburan dengan larutan natrium bikarbonat/SB $\left(\mathrm{NaHCO}_{3}\right)$ 2, 3, dan $4 \%$

e. Pelaburan dengan larutan stanium klorida/ST $\left(\mathrm{SnCl}_{2}\right)$ 2, 3, dan $4 \%$

Pelaburan dengan larutan metilen bistiosianat/MBT $\left(\mathrm{CH}_{2}(\mathrm{SCN})_{2}\right) 2$, 3, dan $4 \%$ sebagai pembanding. Setiap perlakuan disediakan 5 ulangan, sehingga digunakan 150 papan untuk perlakuan dan 30 papan sebagai kontrol (tanpa perlakuan). Kemudian contoh uji dikeringkan di luar ruangan tanpa atap (outdoor) dan di dalam ruangan (indoor) selama kurang lebih 1 
bulan. Pengukuran kelembapan relatif dan suhu udara dilakukan setiap hari selama 4 minggu (Ismanto \& Iqbal, 2013).

\section{Pengukuran Warna}

Pengukuran warna kayu tusam dan kemiri dilakukan 1 bulan setelah perlakuan pelaburan dengan bahan kimia. Pengukuran warna menggunakan Portable Colour Difference Meter model CDX-105. Data hasil pengukuran berupa Yxy (CIE 1931), L*a*b* (CIE 1976), Hunter Lab atau nilai tristimulus $\mathrm{X}, \mathrm{Y}, \mathrm{Z}$ yang diolah melalui pengolah data.

Perbedaan warna dalam 3 titik koordinat dapat dihitung dengan menggunakan persamaan $\Delta E^{*}$ :

$\Delta E^{*}=\left(\Delta L^{*^{2}}+\Delta a^{*^{2}}+\Delta b^{*^{2}}\right)^{-2}$

Keterangan: $\Delta L^{*}, \Delta a^{*}$ dan $\Delta b^{*}$ adalah perbedaan nilai awal $L^{*}, a^{*}$ dan $b^{*}$ dengan nilai akhirnya. Nilai $\Delta E^{*}$ adalah nilai total perbedaan warna. Adapun klasifikasi pengukuran $\Delta E^{*}$ menurut Allegretti et al. (2009) adalah sebagai berikut:

a. $0,2<\Delta \mathrm{E}$ (Tidak terlihat perbedaan)

b. $0,2<\Delta \mathrm{E}<2$ (Perbedaan kecil)

c. $2<\Delta \mathrm{E}<3$ (Perbedaan warna terlihat dengan tampilan berkualitas tinggi)

d. $3<\Delta \mathrm{E}<6$ (Perbedaan warna terlihat dengan tampilan berkualitas sedang)

e. $6<\Delta \mathrm{E}<12$ (Perbedaan warna tinggi)

f. $\Delta \mathrm{E}>12$ (warna berbeda sangat kontras)

\section{Analisis Data}

Perubahan warna pada kayu gergajian dianalisis menggunakan rancangan klasifikasi silang tiga arah (3-way cross classification) yaitu jenis kayu (faktor A), perlakuan kimia (B), dan tempat penyimpanan yakni di luar ruangan dan di dalam ruangan (C). Jika pengaruh faktorfaktor tersebut nyata, maka penelaahan dengan uji beda jarak Duncan (Ott, 1994). Pengolahan data menggunakan komputer dengan program Statistical Analysis System (SAS) 2014.

Model Yijk $=\mu+\mathrm{Ai}+\mathrm{Bj}+\mathrm{Ck}+$ error

Keterangan:

$\mu \quad=$ nilai tengah umum

$\mathrm{Ai}, \mathrm{Bj}, \mathrm{Ck}=$ pengaruh faktor-faktor $\mathrm{A}, \mathrm{B}, \mathrm{C}$
$\mathrm{Y} \quad=$ data perbedaan warna

\section{HASIL DAN PEMBAHASAN}

Hasil perhitungan nilai kecerahan $\left(\mathrm{L}^{*}\right)$ dan perbedaan warna $\left(\Delta \mathrm{E}^{*}\right)$ pada contoh uji kayu tusam dan kemiri pada kontrol (tanpa perlakuan) dan setelah mendapat perlakuan kimia dapat dilihat pada Tabel 1. Hasil pengukuran warna dengan menggunakan Portable Colour Difference Meter pada kelompok contoh uji yang dikeringkan secara alami selama kurang lebih 1 bulan (Tabel 1) menunjukkan adanya perbedaan penampakan warna menurut jenis kayu dan perlakuan.

Secara umum kayu tusam memiliki warna lebih cerah dibandingkan kayu kemiri baik sebelum maupun setelah perlakuan. Hal ini terlihat dari nilai kecerahan warna $\left(\mathrm{L}^{*}\right)$ kayu tusam lebih besar dibandingkan kayu kemiri. Selain itu, dapat dilihat bahwa perlakuan pada contoh uji kedua jenis kayu yang disimpan di dalam ruangan (indoor) memiliki nilai $\mathrm{L}^{*}$ lebih besar dibandingkan contoh uji di luar ruangan (outdoor). Tingginya nilai $\mathrm{L}^{*}$ pada contoh uji kayu di dalam ruangan disebabkan karena pada waktu pengeringan di dalam ruangan tidak terjadi proses oksidasi yang menyebabkan inaktivasi enzim di dalam kayu, sehingga pembentukan warna coklat pada kayu tidak terjadi, hal ini didukung oleh pernyataan Barly et al. (2012) yang mengatakan bahwa pengeringan langsung dengan sinar matahari (di luar ruangan) atau penggunaan suhu tinggi dapat menyebabkan perubahan warna kayu menjadi lebih gelap atau kecoklatan. Namun hasil ini berbeda dengan penelitian yang dilakukan Ilic (1990) dalam Krisdianto (2007), yang mengatakan bahwa permukaan kayu yang terkena udara atau sinar matahari lebih sering menyebabkan warna kayu menjadi lebih terang. Perbedaan ini dapat disebabkan oleh perbedaan jenis kayu maupun perlakuan kimia yang diberikan pada kayu.

Hasil analisis menunjukkan bahwa jenis kayu, perlakuan kimia, dan tempat penyimpanan contoh uji berpengaruh nyata terhadap perbedaan warna $(\mathrm{P} \leq 0,05)$. Pada Tabel 2, disajikan hasil analisis nilai 
perbedaan warna pada kayu. Sedangkan hasil analisis sidik ragam pengaruh perlakuan kimia dicantumkan pada Tabel 3. Besarnya nilai $\Delta \mathrm{E}^{*}$ menunjukkan ketidakseragaman warna permukaan kayu, hal ini tentu saja akan berdampak pada rendahnya penilaian konsumen terhadap kayu yang selama ini memiliki persepsi bahwa papan yang memiliki warna yang seragam lebih tinggi kualitasnya daripada papan yang memiliki variasi warna tinggi.

Tabel 1. Nilai Kecerahan $\left(\mathrm{L}^{*}\right)$ dan Perbedaan Warna $\left(\Delta \mathrm{E}^{*}\right)$ pada Kayu Tusam dan Kemiri

\begin{tabular}{|c|c|c|c|c|c|c|}
\hline \multirow{2}{*}{$\begin{array}{l}\begin{array}{l}\text { Perlakuan } \\
\text { (Treatment) }\end{array} \\
\begin{array}{l}\text { Di luar ruangan } \\
(\text { outdoor })\end{array}\end{array}$} & \multicolumn{3}{|c|}{ Kayu tusam (Pine wood) } & \multicolumn{3}{|c|}{ Kayu kemiri (Pecan wood) } \\
\hline & $\mathrm{L}^{*}$ & $\Delta \mathrm{L}^{*}$ & $\Delta \mathrm{E}^{*}$ & $\mathrm{~L}^{*}$ & $\Delta \mathrm{L}^{*}$ & $\Delta \mathrm{E}^{*}$ \\
\hline K & 72,6 & $-21,2$ & 34 & 72,6 & $-21,2$ & 40,1 \\
\hline $\mathrm{SC}$ & 72,1 & $-21,7$ & 34 & 63 & $-30,8$ & 44,9 \\
\hline SS & 71,8 & -22 & 26,3 & 61,4 & $-32,4$ & 44,8 \\
\hline SB & 70,6 & $-23,2$ & 32,9 & 56,6 & $-37,2$ & 44,9 \\
\hline ST & 71,4 & $-22,4$ & 34,4 & 62,8 & -31 & 43,3 \\
\hline MBT & 74 & $-19,8$ & 31,2 & 66,1 & $-27,7$ & 40,5 \\
\hline $\begin{array}{l}\text { Di dalam ruangan } \\
\text { (indoor) }\end{array}$ & $\mathrm{L}^{*}$ & $\Delta \mathrm{L}^{*}$ & $\Delta \mathrm{E}^{*}$ & $\mathrm{~L}^{*}$ & $\Delta \mathrm{L}^{*}$ & $\Delta \mathrm{E}^{*}$ \\
\hline K & 72,6 & $-21,2$ & 28,2 & 72,6 & $-21,2$ & 25,2 \\
\hline $\mathrm{SC}$ & 77,4 & $-16,4$ & 29,7 & 65,4 & $-28,4$ & 41,2 \\
\hline SS & 72,7 & $-21,1$ & 33,7 & 63,4 & $-30,4$ & 44,2 \\
\hline SB & 70,7 & $-23,1$ & 33,3 & 66,5 & $-27,3$ & 41,6 \\
\hline ST & 75,4 & $-18,4$ & 32,1 & 64,2 & $-29,6$ & 44,4 \\
\hline MBT & 78,1 & $-15,7$ & 29,1 & 67,7 & $-26,1$ & 42,5 \\
\hline
\end{tabular}

Keterangan (Remarks) $: \mathrm{K}=$ kontrol (Untreated), $\mathrm{SC}=$ natrium klorida (SodiumChloride), $\mathrm{SS}=$ natrium sulfit (Sodium Sulphite), $\mathrm{SB}=$ natrium bikarbonat (Sodium Bicarbonate), $\mathrm{ST}=$ staniumklorida $($ Stanium Chloride), $\mathrm{MBT}=$ metilen bis-tiosianat (Methylene bis-Thiocyanate)

Tabel 2. Hasil Analisis Nilai Perbedaan Warna pada Kayu

\begin{tabular}{lccccc}
\hline $\begin{array}{l}\text { Sumber keragaman } \\
\text { Source of variation) }\end{array}$ & $\begin{array}{l}\mathrm{db} \\
(d f)\end{array}$ & $\begin{array}{l}\text { Jumlah } \\
\text { kuadrat } \\
\text { (Sum of } \\
\text { squares })\end{array}$ & $\begin{array}{l}\text { Kuadrat } \\
\text { tengah } \\
\text { (Means } \\
\text { square) }\end{array}$ & $\begin{array}{l}\mathrm{F} \text { hitung } \\
\text { calculation) }\end{array}$ & $\underline{\operatorname{Pr}>\mathrm{F}}$ \\
\hline Model & 7 & 736,72125 & 105,24589 & 6,70 & 0,0008 \\
Galat (Error) & 16 & 251,29833 & 15,70615 & & \\
Total (Total) & 23 & 988,01958 & & & \\
\hline $\mathrm{R}^{2}(R$ square) $=0,74566$ & & & \\
Koef. Keragaman (Coeff. of variation $)=10,85161$ &
\end{tabular}


Tabel 3. Analisis Sidik Ragam Pengaruh Perlakuan terhadap Perbedaan Warna

\begin{tabular}{|c|c|c|c|c|c|}
\hline $\begin{array}{l}\text { Sumber keragaman } \\
\text { (Source of variation) }\end{array}$ & $\begin{array}{l}\mathrm{db} \\
(d f)\end{array}$ & $\begin{array}{l}\text { Jumlah } \\
\text { kuadrat } \\
\text { (Sum of } \\
\text { squares) }\end{array}$ & $\begin{array}{l}\text { Kuadrat } \\
\text { tengah } \\
\text { (Means } \\
\text { square) }\end{array}$ & F value & $\mathrm{Fr}>\mathrm{F}$ \\
\hline $\begin{array}{ll}\text { Jenis kayu } & \text { (Wood } \\
\text { species), A } & \end{array}$ & 1 & 587,07042 & 587,07042 & 37,38 & 0,0001 \\
\hline $\begin{array}{l}\text { Perlakuan } \\
\text { (Chemicals } \\
\text { treatment), B }\end{array}$ & 5 & 121,26708 & 24,25342 & 1,54 & 0,2319 \\
\hline $\begin{array}{l}\text { Tempat penyimpanan } \\
\text { (Storage), C }\end{array}$ & 1 & 28,38375 & 28,38375 & 1,81 & 0,1976 \\
\hline
\end{tabular}

Berdasarkan uji beda Duncan $(\mathrm{P}<0,05)$, kayu kemiri memiliki perbedaan $(\Delta \mathrm{E})$ warna yang lebih besar $(41,47)$ dibandingkan dengan perbedaan warna pada kayu tusam yakni 31,58. Perlakuan kimia pada kayu memberikan pengaruh perubahan warna yang berbeda menurut jenis kayu dan bahan kimia yang digunakan. Berdasarkan uji beda Duncan (P $<0,05$ ) pada contoh uji kontrol (tidak dilabur bahan kimia) didapatkan nilai perbedaan warna paling rendah yaitu 31,88 . Sedangkan nilai perbedaan warna tertinggi diperoleh pada kayu yang dilabur stanium klorida (ST), dan perlakuan kimia lainnya tidak menunjukkan perbedaan yang nyata (Tabel 4). Hal ini berarti bahwa bahan kimia ST tidak cocok untuk stabilisasi warna kayu. Nilai perbedaan warna pada perlakuan lainnya tersebut lebih rendah, sehingga berpotensi dalam mempertahankan warna alami kayu.
Larutan kimia SC, SS, SB dan MBT memiliki kemampuan dalam menetralisir pH, dan menurut Lukmandaru et al. (2015), nilai $\mathrm{pH}$ umumnya dalam kisaran asam terdapat zat fenolat yang bertindak sebagai asam lemah. Kandungan fenolat akan diendapkan sehingga memberikan warna yang lebih cerah $\left(\Delta \mathrm{E}^{*}\right.$ lebih kecil). Hal ini menunjukkan bahwa larutan kimia SC, SS, SB, dan MBT dapat mempertahankan warna alami kayu walaupun masih terbatas baik pada jenis kayu maupun tempat penyimpanannya. Secara umum larutan bahan kimia yang digunakan dalam penelitian ini khususnya pada kayu tusam dapat menurunkan nilai $\Delta \mathrm{E}^{*}$ terutama di luar ruangan (outdoor), seperti natrium klorida (SC), natrium sulfit (SS), natrium bikarbonat (SB) dan metilen bis-tiosianat (MBT).

Tabel 4. Rata-Rata Nilai Perbedaan Warna pada Kayu

\begin{tabular}{clc}
\hline $\begin{array}{c}\text { No. } \\
(\text { Number })\end{array}$ & $\begin{array}{c}\text { Perlakuan kimia }(\text { Chemicals } \\
\text { treatment })\end{array}$ & $\begin{array}{c}\text { Nilai perbedaan warna (Color differences } \\
\text { value })\end{array}$ \\
\hline 1. & Kontrol (Untreated $)$ & $31,88 \mathrm{~b}$ \\
2. & Natrium klorida $(S C)$ & $37,45 \mathrm{ab}$ \\
3. & Natrium sulfit $(S S)$ & $37,25 \mathrm{ab}$ \\
4. & Natrium bikarbonat $(S B)$ & $38,18 \mathrm{ab}$ \\
5. & Stanium klorida $(S T)$ & $38,55 \mathrm{a}$ \\
6. & Metilen bis-tiosianat $(M B T)$ & $35,83 \mathrm{ab}$ \\
\hline
\end{tabular}

Keterangan (Remark): Angka-angka pada lajur yang diikuti oleh huruf sama tidak berbeda nyata pada uji Duncan $(\mathrm{P} \leq 0,05)$. 
Berdasarkan Tabel 4, dapat diketahui bahwa jenis bahan kimia berpengaruh nyata terhadap nilai perbedaan warna kayu $\left(\Delta \mathrm{E}^{*}\right)$. Hal ini menunjukkan bahwa untuk menjadikan warna kayu lebih seragam diperlukan jenis bahan kimia yang sesuai dalam penggunaannya. Larutan kimia SC, $\mathrm{SS}, \mathrm{SB}$, dan MBT dapat menurunkan nilai $\Delta \mathrm{E}^{*}$, sehingga dapat berpotensi mempertahankan warna alami kayu walaupun masih terbatas baik pada jenis kayu maupun tempat penyimpanannya. Didapatkan bahwa nilai perbedaan warna pada kayu yang disimpan di luar ruangan lebih besar yaitu 37,61 dibandingkan dengan nilai perbedaan warna pada kayu yang disimpan di dalam ruangan yakni 35,43, namun tidak menunjukkan perbedaan yang nyata $(\mathrm{P}<$ 0,05). Hal ini disebabkan waktu yang digunakan dalam penelitian ini relatif singkat sehingga tidak memberikan pengaruh yang nyata dalam pewarnaan kayu. Menurut Ilic (1990) dalam Krisdianto (2007), penelitian seharusnya dilakukan selama satu tahun, sehingga kondisi bulan basah dan bulan kering terwakili.

Pengeringan kayu dapat dipengaruhi oleh panas (suhu) dan kelembapan relatif (relative humidity/rH). Data suhu dan kelembapan relatif $(\mathrm{rH})$ udara tempat penyimpanan contoh uji kayu di luar dan dalam ruangan disajikan pada Tabel 5 .

Kelembapan relatif $(\mathrm{rH})$ rata-rata di luar ruangan lebih rendah dibandingkan dengan tempat penyimpanan di dalam ruangan, sedangkan suhu rata-rata di luar ruangan lebih tinggi $\left(29^{\circ} \mathrm{C}\right)$ dibandingkan dengan suhu di dalam ruangan $\left(23^{\circ} \mathrm{C}\right)$. Menurut Rice et al. (2008), suhu optimum untuk pertumbuhan jamur biru berkisar antara $20-25^{\circ} \mathrm{C}$. Hal ini menjadi salah satu faktor penyebab contoh uji kayu yang disimpan di dalam ruangan cenderung rentan terhadap serangan jamur biru, ditambah lagi rHnya yang lebih tinggi.

Kadar air kayu merupakan salah satu faktor yang mempengaruhi tingkat kerentanan kayu terhadap serangan jamur biru (blue stain) (Carey, 1975 dalam Martono, 2012). Hasil pengukuran kadar air dan kehilangan berat pada kayu tusam dan kemiri di tempat terbuka (outdoor) dan dalam ruangan (indoor) dapat dilihat pada Tabel 5.

Kayu tusam mempunyai kandungan gum tinggi yang membentuk gel, larutan ataupun suspensi kental dengan konsentrasi rendah, sehingga dapat menahan kadar air dalam serat dan memicu tumbuhnya jamur blue stain (Koch, 2008). Selain itu, menurut Ilic (1990) dalam Krisdianto (2007), bahwa kadar air tinggi menyebabkan warna kayu menjadi lebih terang, sehingga peryataan ini mendukung hasil data yang diperoleh bahwa kayu tusam memiliki nilai L* lebih tinggi dibandingkan kayu kemiri.

Tabel 5. Kadar Air Kayu, Kelembapan Relatif, Suhu Udara di Tempat Penyimpanan

\begin{tabular}{|c|c|c|c|c|c|c|}
\hline \multirow[t]{2}{*}{$\begin{array}{l}\text { Tempat } \\
\text { penyimpanan }\end{array}$} & \multicolumn{3}{|c|}{$\begin{array}{l}\text { Kayu } \\
\text { Tusam }\end{array}$} & \multicolumn{3}{|c|}{$\begin{array}{l}\text { Kayu } \\
\text { kemiri }\end{array}$} \\
\hline & $\begin{array}{c}\text { Kadar air } \\
(\%)\end{array}$ & $\begin{array}{l}\text { Kelemb } \\
\text { apan } \\
\text { relatif } \\
\text { udara, } \\
\%\end{array}$ & $\begin{array}{l}\text { Suhu } \\
\text { udara } \\
\text { (Air } \\
\text { temperat } \\
\text { ure), }{ }^{\text {C }}\end{array}$ & $\begin{array}{l}\text { Kadar } \\
\text { air } \\
(\%)\end{array}$ & $\begin{array}{l}\text { Kelemb } \\
\text { apan } \\
\text { relatif } \\
\text { udara, } \\
\%\end{array}$ & $\begin{array}{l}\text { Suhu } \\
\text { udara } \\
\text { (Air } \\
\text { temper } \\
\text { ature), } \\
\text { C }\end{array}$ \\
\hline Di luar ruangan & 29,14 & $72 \pm 2,5$ & $29 \pm 2,6$ & 17,55 & $72 \pm 2,5$ & $29 \pm 2,6$ \\
\hline Di dalam ruangan & 24,23 & $80 \pm 2,8$ & $23 \pm 2,3$ & 19,94 & $80 \pm 2,8$ & $23 \pm 2,3$ \\
\hline Rata-rata & 26,70 & $76 \pm 2,6$ & $26 \pm 2,4$ & 18,75 & $76 \pm 2,6$ & $26 \pm 2,4$ \\
\hline
\end{tabular}

Keterangan : \pm : Standar deviasi 


\section{KESIMPULAN}

Secara umum kayu tusam dan contoh uji yang disimpan di dalam ruangan memiliki nilai kecerahan $\left(\mathrm{L}^{*}\right)$ lebih tinggi dibandingkan dengan kayu kemiri dan contoh uji yang disimpan di luar ruangan. Perlakuan kimia yaitu SS, SB dan MBT dapat menurunkan perbedaan warna sehingga berpotensi dalam mempertahankan warna alami kayu.

\section{DAFTAR PUSTAKA}

Allegretti, O., L. Travan, R. Cividini. 2009. Drying techniques to obtain white beech. Proceedings of EDG Conference, 23 April 2009. Bled, Slovenia: 7-13.

Barly, B., D. Martono, A. Abdurachman. 2012. Pengawetan warna kayu tusam dan pulai dengan menggunakan bahan dasar disinfektan. Jurnal Penelitian Hasil Hutan. 30 (2): 155-162.

de Guzman, C.C., \& J. S. Siemonsma. 1999. Plant resources of SouthEast Asia, No.13. Spices. Backhuys Publishers. Leiden.

Dubey, K. M., S. Pang, J. Walker. 2010. Color and dimensional stability of oil heat-treated radiata pinewood afer accelerated UV weathering. Forest Prod. J. 60 (5): 453-459.

Ismanto, A \& M. Iqbal. 2013. Pencegahan perubahan warna pada kayu jamuju (Podocarpus imbricatus) dan kisampang (Evodia aromatica BL.) dengan bahan dasar desinfektan. Jurnal Penelitian Hasil Hutan. 31 (3). 213-220.

Koch, G. 2008. Discoloration of wood in the living tree and during processing. Proceedings of Conference COST E53, 29-30
October 2008, Delf, The Netherlands: 11-18.

Krisdianto. 2007. Colour differences of pine and eucalyptus. Journal of Forestry Research. 4 (2): 83-91.

Lemmens, R. H. M. J., I. Soerianegara, W. C. Wong. 1994. Timber trees: Major commercial timbers No 5 (1). Pudoc, Wageningen. 1994/Prosea, Bogor.

Lukmandaru, G., S. Fatimah, A. Fernandes. 2015. Sifat kimia dan warna kayu keruing, mersawa dan kapur. Jurnal Penelitian Ekosistem Dipterokarpa. 1 (2): 69-80.

Martono, D. 2012. Peranan pengawetan propilaktik dalam efisiensi pemanfaatan bahan kayu dan lignoselulosa lain. Himpunan Karya Ilmiah. Badan Litbang Kehutanan-Kementerian Kehutanan. Bogor: 129-151.

Ott, R. L. 1994. An Introduction to Statistical Methods and Data Analysis. Duxbury Press. Belmont, CA. USA.

Rice, A.V., M. N. Thormann, D. W. Langor. 2008. Mountain pine beetle-associated blue stain fungi are differentially adapted to boreal temperatures. For. Pathol. 38 (2): 113-123.

Wenli, T \& W. Yiqiang. 2010. Study on discolorization technology of Paulonia timber suitable middle and small wood Processing Enterprises. Collage Materials Sciences and Engineering. Central South University of Forestry and Technology. Chengsha, China.

Uzunovic, A., T. Byrne, M. Gicnac, Y. Dian-Qing. 2008. Wood Discolourations and their Prevention. F.P. Innovations. Canada. 